\title{
AS TIPOLOGIAS DA ARQUITETURA ESCOLAR NO BRASIL E O CASO DA ESCOLA MUNICIPAL CATARINA MARTINS ARTERO EM PRESIDENTE PRUDENTE-SP
}

\author{
Korina Costa; Anelise Zandona; Beatriz Galvão \\ Universidade do Oeste Paulista - UNOESTE, Faculdade de Engenharias e Arquitetura e Urbanismo, \\ Presidente Prudente, SP. E-mail: korina.arq@gmail.com
}

\begin{abstract}
RESUMO
Este trabalho tem como objetivo identificar a tipologia arquitetônica da Escola de Ensino Fundamental I da cidade de Presidente Prudente, chamada de Escola Municipal Professora Catarina Martins Artero. Para isso foi feita uma pesquisa qualitativa, iniciada pela retomada teórica e histórica das tipologias arquitetônicas de diferentes épocas, considerando as políticas públicas educacionais e a sociedade, além da vertente arquitetônica de cada período, identificamos período da construção da edificação escolar com base em levantamentos in loco, de documentos e registros disponibilizados pela escola em estudo. Constatamos que a escola possui projeto dos anos sessenta, assim apresenta características modernistas em seus elementos construtivos e na organização de sua planta baixa.

Palavras-Chave - Arquitetura Escolar, Escola Municipal Professora Catarina Martins Artero, Estudo de Caso, Arquitetura Modernista, Retomada Histórica.
\end{abstract}

\section{THE TYPES OF SCHOLAR ARCHITECTURE IN BRASIL AND THE CASE OF MUNICIPAL SCHOOL PROFESSOR CATARINA MARTINS ARTERO IN PRESIDENTE PRUDENTE-SP}

\begin{abstract}
This work aims to identify the architectural typology of Elementary School in the city of Presidente Prudente, called Escola Municipal Professora Catarina Martins Artero. To that, a qualitative survey was conducted, initiated by the theoretical and historical recovery of the architectural typologies of different times, considering the educational public policy and society. Besides the architectural aspects of each period, also identified the period of school building construction based on surveys on site, documents and records provided by the school under study. We found that the school has design of the sixties, and has modernist features in their construction elements and organization of your floor plan.

Keywords - Scholar architecture, Municipal School Professor Catarina Martins Artero, Case Study, Modern Architecture, Historical Resumption.
\end{abstract}




\section{INTRODUÇÃO}

Em uma área urbana, os serviços, equipamentos urbanos e infraestrutura são essenciais para a comunidade. Dentre os serviços de responsabilidade governamental, encontra-se a rede de ensino. De acordo com a Constituição Brasileira de 1988, é de competência dos Estados e Municípios proverem escolas, vagas, estruturas e docentes para ensino fundamental nas cidades, visando atender outras especificidades.

Vale destacar que, no Estado de São Paulo o Ensino Fundamental I foi municipalizado ná década de 1990, quando a rede de ensino passa a ser dividida em: Educação Infantil (que atende crianças de 0 a 6 anos, sendo de responsabilidade Municipal); Ensino Fundamental I (de primeiro a quinto ano, sendo de responsabilidade Municipal); Ensino Fundamental II (de sexto a nono ano, sendo de responsabilidade Estadual); Ensino Médio (de primeiro a terceiro ano, sendo de responsabilidade Estadual) e Educação Superior (varia entre as responsabilidades Estadual e Nacional).

Cujo objeto de estudo da presente pesquisa centra-se em uma edificação escolar pública pertencente ao Ensino Fundamental I, que compreende crianças de 6 a 10 anos, o que torna importante verificar se a mesma está adequada para o ensino e aprendizagem de tal faixa etária, com equipamentos que possibilitem seu desenvolvimento social, cognitivo, educacional e motor.

Assim, o objetivo da pesquisa foi fazer o levantamento da situação atual da Escola Municipal Professora Catarina Martins Artero, tendo como foco a relação da tipologia da edificação com as teorias pedagógicas em vigor, além da possibilidade de relacionar o edifício ao estilo arquitetônico vigente na época e às políticas públicas educacionais.

\section{METODOLOGIA}

A metodologia utilizada nesta pesquisa é a qualitativa, cujo procedimento de estudo perpassou pelo estudo teórico, retomou os direcionamentos pedagógicos do período da construção da edificação escolar, assim como a elaboração dos conceitos e da investigação prática por meio de levantamentos de documentos e registros disponibilizados pela escola e pela coleta e investigação através da pesquisa de campo, seguido pelo mapeamento dos mesmos e sua análise, enquadrando-se como um estudo de caso.

O que se deu mediante o pensamento de Teixeira (2000), que define que o estudo de caso deve ter como procedimento de pesquisa a sequência que se inicia pela fase explanatória e de definição do objeto de estudo, seguida pela delimitação do alcance da pesquisa, o que compreende o estudo teórico e de retomada de autores e pesquisadores da temática, seguida pela coleta de dados, efetuada de maneira individualizada e atenta ao universo ao qual pertence o objeto de estudo, o que possibilitou ao pesquisador adentrar na última fase da pesquisa que permitiu que se faça as análises, através do cruzamento dos conceitos teóricos e das observações da prática, feitas durante o levantamento dos dados.

\section{RESULTADO DO ESTUDO SOBRE HISTÓRIA DAS EDIFÍCAÇÕES ESCOLARES NO BRASIL}

No período colonial, pouco se fez em relação à educação escolarizada no Brasil, o que, segundo Santos (2012), explica-se pela organização social e política, que não se pautava em uma mão de obra letrada, estando muito mais voltada para as atividades extrativas. De acordo com Kowaltowski (2011) foi a partir do Brasil Império, que se pôde constatar uma primeira preocupação educativa em território nacional, esta, direcionada para a formação da elite dirigente, o que refletiu no surgimento do sistema de Ensino Superior, momento este em que não havia uma grande preocupação com a educação formativa dos níveis de letramento e das camadas menos abastadas doa sociedade. Anos depois, no Brasil republicano, o padrão pedagógico e arquitetônico tornou-se unificado para todo o país, apresentando marcas que representam a herança do Brasil império, através das "escolas de ler e escrever" que na maior parte das vezes eram a extensão da 
casa do professor, funcionando em paróquias, cômodos de comércio, em salas poucos ventiladas e pouco iluminadas" (BUFFA e PINTO 2002, apud KOWALTOWSKI, 2011, pg. 80).

Ainda nesse período histórico, visando atender à vontade populacional de melhoria da qualidade de vida e possibilidade de ascensão social pela educação formal, deu-se início ao processo de organização do espaço educacional, promovendo o estreitamento do vínculo entre o edifício escolar e os conceitos educacionais. Foi assim que surgiram as primeiras escolas primárias de responsabilidade governamental, que se organizavam em classes sequenciais (KOWALTOWSKI, 2011). Na busca de encontrar referências para a construção de tais edifícios, foi feito uso do manual School Architecture, escrito entre 1838 e 1840, por Henry Barnard, Superintendente das Common Schools de Connecticut, publicado em 1854, que contribuiu para divulgar a nova concepção de que os prédios escolares deveriam ser cuidadosamente planejados com a participação dos educadores (BUFFA, 2015).

Tal influência Norte-Americana, aumenta com o fim da Primeira Guerra Mundial, quando intelectuais brasileiros em contato com o movimento Escola Nova, fundaram em 1924 a Associação Brasileira de Educação (ABE), que propunha reformas ao sistema de ensino. (XAVIER; RIBEIRO; NORONHA, 1994 apud SANTOS, 2012, pg. 04). Após muitas crises, incluindo a crise de 1929, o Brasil passa a formular uma política econômica voltada para a industrialização. (BUFFA, 2015), assim, a partir de 1930, houve a reorganização do sistema educacional brasileiro, quando se observa que a sociedade política passa a atuar de forma cada vez mais intensa na sociedade civil, submetendo-a ao seu controle (SANTOS, 2012).

O que, conforme Kowaltowski (2011), foi reforçado pela primeira Constituição brasileira, datada de 1937, que obrigava os municípios a investir 10\% da arrecadação tributária em educação, construção e manutenção de prédios escolares. Momento este, em que o Estado introduz o ensino profissionalizante para as classes sociais menos privilegiadas (Art. 129, apud FREITAG, 2007, PG. 90), conferindo direcionamentos para que as indústrias e sindicatos criem escolas de aprendizagem na área de sua especialização para os filhos dos empregados e membros e declara obrigatória as disciplinas de educação moral e política. (Art. 131 apud FREITAG, 2007, pg. 90). O que evidencia que a política do Estado Novo busca transformar o sistema educacional em um instrumento eficiente de manipulação das classes trabalhadoras. (FREITAG, 2007)

Segundo Buffa (2015) os processos de industrialização e urbanização iniciados nas décadas anteriores levaram a formação de uma nova classe social, composta por trabalhadores urbanos e operários. Houve também uma expansão das camadas médias da sociedade, devido ao crescimento do setor terciário e início da formação de uma burguesia industrial. Estes fatores levaram a explosão de crescimento da população nas capitais e assim intensificou-se a falta de escolas para atender tal crescimento da demanda. Nessa época passa-se a ter uma preocupação com as condições higiênicas dos prédios escolares, caracterizado pela arquitetura moderna dos anos 30, quando se evidencia os conceitos racionalistas como: a linguagem formal simples e geométrica, sem ornamentação, com aberturas horizontais (janelas longitudinais), assim como a integração dos espaços internos e externos, e ainda, grandes corredores para uma boa circulação, conforme as propostas do funcionalismo arquitetônico. (RAIMANN, 2008, apud KOWALTOWSKI, 2011).

Tal crescimento da industrialização tornou de São Paulo "o mais importante polo industrial do País, o que significa novas demandas socioeconômicas", conforme apresenta Kowaltowski (2011, pg. 88). Tanto a cidade como o Estado de São Paulo, passaram por um grande crescimento da industrialização e urbanização, e consequentemente houve aumento na demanda por educação, novas escolas e uma maior necessidade de melhorias no sistema de ensino. (BUFFA, 2002). Assim, em 1949, foi criado o "Convênio Escolar", estabelecido entre as admirações do Estado e do Município de São Paulo, dando início a um novo período da história da arquitetura escolar paulista (FDE, 1998a, 1998d, apud KOWALTOWSKI, 2011). 
Nas décadas de 1950 a 1960 têm-se um período que Xavier; Ribeiro; Noronha apud Santos (2012, pg. 6) chamam de "capitalismo monopolista", em que o futurismo de Juscelino Kubitschek derrubou o nacionalismo existente e preparou o país para a internacionalização da economia. Com uma acelerada urbanização, o mercado de trabalho passou a necessitar de mão de obra especializada, promovendo o avanço construtivo de escolas, com rapidez executiva e com pouca verba, culminando em padronagens projetuais e pouca qualidade construtiva, na qual faltavam detalhamentos e especificações de acabamento. (ORNSTEIN; BORELLI , 1995 aput KOWALTOWSKI, 2011, pg. 90)

Para Buffa (2015) as décadas destacadas acima, foram de extrema significância pelas inovações nas técnicas construtivas de pré-fabricação e uso de estruturas em concreto, decorrentes da arquitetura moderna, pela continuidade das tendências pedagógicas vigentes, cujas referências arquitetônicas dividiam-se em duas vertentes, a Escola Carioca e a Escola Paulista. Cuja primeira tinha como base as produções de Lúcio Costa, Oscar Niemeyer e Reidy, arquitetos estes que projetaram edificios de forma singular e inovadora, levando a produção nacional ao conhecimento mundial.

Em São Paulo, a Escola Paulista, através da influência dos ex-alunos da Escola Politécnica, também seguiam as diretrizes da arquitetura moderna, porém com percursos diferentes, o que resultou em uma linguagem também única. Sua maior referência foi Vilanova Artigas, cuja produção propiciou a criação de uma normatização de componestes e geometrias nos prédios, modulação da planta baixa e da área destinada a cada ambiente da escola.

Tais discussões e propostas influenciaram nas atuais normatizações recomendadas para o Estado de São Paulo, as quais passam pelo controle da Secretaria de Educação do Estado.( Kowaltowski, 2011).e estabececem: "[o] dimenssionamento das salas foi estabelecido em 51,84 $\mathrm{m}^{2}$ de área construída para as salas de aula comuns ou multiúso, e de $77,76 \mathrm{~m}^{2}$ para as salas de aula prática. As dimensões em planta para as salas comuns eram de 7,20 m x 7.20 m, de eixo a eixo"( Conesp, 1985 apud Kowaltowski, 2011, pg. 91).

Vale reforçar, que mesmo com o vigente aumento da construção de escolas, este período também foi marcado pela falta das mesmas, já que a demanda pela educação crescia mais que a oferta de ensino, que também se encontrava mal distribuída pelos municípios. (BUFFA, 2015), o que levou o Estado de São Paulo a produzir escolas de maneira rápida, de baixo custo, através de um sistema construtivo simplificado, cuja planta possuía um grande corredor que dava acesso às dependências escolares com paredes de alvenaria de blocos aparentes de concreto, o teto de laje pré-moldada com cobertura de telhas de fibrocimento (XAVIER; LEMOS; CORONA, 1983 apud KOWALTOWSKI 2011). A simplicidade dos materiais é consequência da política governamental de diminuir custos e prazos de construção e os novos métodos construtivos possibilitaram uma estrutura independente da vedação, o que proporcionava uma planta livre dos limites estruturais convencionais, além disso os poucos pilares internos fizeram surgir grandes espaços livres cobertos e blocos de atividade separados que garantiam uma melhor ventilação e iluminação dos espaços internos. (BUFFA, 2015)

Em 1976 foi fundada a Companhia de Construções de São Paulo (Conesp), que listava os itens necessários para a produção dos projetos, direcionava o seu desenvolvimento e a execução das obras escolares, estas decorrentes de licitações públicas, variantes entre novas obras e reformas das edificações existentes (ORNSTEIN; BORELLI , 1995 apud KOWALTOWSKI ,2011), sendo esta a alternativa encontrada para economizar sem ter que apenas produzir projetos padrão, assim a Conesp preferiu usar projetos com normatização de componentes e geometrias do prédio escolar e seus ambientes, modulando o projeto em $90 \mathrm{~cm} \times 90 \mathrm{~cm}$, permitindo que os arquitetos procurassem "soluções adequadas a cada local e a cada situação, pelo sistema de padronização, que definia dimensões, processos e materiais" (KOWALTOWSKI,2011, pg. 91). 


\section{DISCUSSÃO SOBRE A ESCOLA CATARINA MARTINS ARTERO DE PRESIDENTE PRUDENTE}

Presidente Prudente está localizada a 559 km de São Paulo e foi declarada município em 28 de novembro de 1921 pelo Presidente Washigton Luís. A cidade inicialmente foi formada pela união de povoados, sendo eles a Vila Marcondes e o povoado de Coronel Marcondes, aberto em 1919, é nesse ano que foi inaugurada a Estação Ferroviária, local que passa a marcar o crescimento da cidade. (RESENDE, 2012). Três anos após o início da formação do povoado, Presidente Prudente inaugurou sua primeira estrutura educacional, segundo o modelo das Escolas Reunidas, cuja estrutura contava com poucas salas de aula e dividia os alunos de acordo com o gênero (EMUBRA, 2016). Em 1925 criou-se o primeiro Grupo Escolar da cidade, que recebeu o nome de Grupo Escolar Professor Arruda Melo (RESENDE, 2012).

A escola Catarina Martins Artero foi inaugurada em 1974 na Vila Maristela, atualmente conta com 175 alunos, 12 funcionários, 20 professores e 4 estagiários. Não foi possível encontrar os documentos que registrassem o período efetivo de construção e projeto da escola, mas a partir das análises que relacionam o conhecimento decorrente da revisão bibliográfica e a observação da edificação, verificou-se que o edifício possui características da arquitetura escolar produzida mediante os conceitos que marcavam os direcionamentos dos anos 60.

Os elementos que levaram à constatação de que o projeto apresenta características de tal período, foram a forma geométrica, os elementos vazados no corredor e salas de aula e o uso dos equipamentos urbanos, pois segundo Buffa (2015) nota-se que o partido arquitetônico nessa época era a cidade, os corredores passam a ser mais iluminados e ventilados e os equipamentos urbanos são distribuídos pela escola para encontro e lazer dos alunos.

A disposição dos banheiros em relação às salas de aula e também da biblioteca em relação às salas de aula também foram constatações que vinculam a escola aos preceitos educacionais da década de 60, mesmo tendo sido executada na década de 70. Buffa (2015), ressalta que nessa época os arquitetos eram contratados para produzir os projetos arquitetônicos, os projetistas se atentavam essencialmente para o uso de materiais contemporâneos e para a funcionalidade do projeto.

A escola permanece da forma que foi construída, em relação à disposição dos ambientes, houveram apenas algumas alterações na reforma de 2006, em que a cobertura do edifício foi reestruturada, o forro que era de madeira passou a ser de PVC, a edificação foi pintada para seguir as normas da Fundação de Desenvolvimento da Educação (FDE), que fundamenta que as escolas de ensino integral sejam pintadas na cor azul. Na última reforma, ocorrida em 2007, a quadra poliesportiva foi coberta e a escola passou a ter elementos de acessibilidade, como rampas, banheiros com equipamentos adequados, tamanho das aberturas e nivelamentos de piso.

Através do levantamento decorrente da primeira visita à escola, foi constatada a necessidade de haver uma área recreativa para as crianças, um espaço adequado para o armazenamento de materiais de limpeza, pois estes encontravam-se guardados em local aberto, podendo ser alcançado pelos alunos. Observou-se também a necessidade de trocar as carteiras dos alunos do $1^{\circ}$ ano, pois as existentes não estão adequadas para o tamanho dos mesmos. Porém, após algumas visitas nos deparamos com mudanças, a escola instalou novos equipamentos de recreação, passaram a fechar o depósito de materiais de limpeza e trocaram as carteiras das crianças, mantendo em aberto a necessidade de um local adequado para as atividades das crianças, sendo uma prática acadêmica tão importante quanto as desenvolvidas dentro das salas de aula.

\section{CONCLUSÃO}

Com a presente pesquisa pôde-se constatar que a tipologia arquitetônica das escolas públicas são o reflexo das políticas públicas e das necessidades da sociedade da época em que foi projetada, assim, após o levantamento da situação atual da escola em análise e do estudos de 
diferentes vertentes arquitetônicas, concluímos que a E. M. Profa. Catarina Martins Artero possui características modernistas, evidenciadas pela presente preocupação com o conforto térmico das salas de aula, onde existe ventilação cruzada e o uso do cobogó, elemento característico da produção modernista brasileira, nos corredores das salas de aula.

Pode-se dizer, que foi a partir da década de sessenta que se buscou uma maior interação do ambiente escolar e o meio urbano no qual a mesma está inserida, sendo assim, foram implantados na escola bancos de concreto de característica padronizada. Outro ponto relevante para a definição de que a escola apresenta reflexos do pensamento educacional e arquitetônico da década em questão, se concentra na organização da escola, que contém em sua planta os preceitos modernos, quando os projetistas se concentram em promover espaços funcionais ,sanitaristas e sem um vínculo direto com os anseios dos demais profissionais ligados à educação, na contemporaneidade, tais pensamentos podem ser refletidos na busca de aproximar as crianças dos banheiros, por uma questão de logística em que diminui o tempo de deslocamento de um local ao outro, e da biblioteca, por uma questão de incentivo à pesquisa e leitura.

\section{REFERÊNCIAS:}

BUFFA, Ester ,Grupos escolares paulistas: organização do espaço e propostas pedagógicas (18931971), Universidade Federal de São Carlos / Disponível em: http://pgsskroton.com.br/index.php Acesso em: 30. Jun. 16

EMUBRA, Enciclopédia dos Municípios Brasileiro, Ensino, Disponível em: < http://camarapprudente.sp.gov.br/historia/hist_oeste/cidades/pprudente/ensino.html > Acesso em: 30 jun. 16

FREITAG, Barbara. Escola Estado e Sociedade. 7. ed. São Paulo: Centauro,2005 KOWALTOWSKI, Doris C. C. K., Arquitetura escolar o projeto do ambiente de ensino, São Paulo: Oficina de Textos, 2011

RESENDE, Benjamin Teodoro de, Raízes Prudentinas/ 3 ed. , São Paulo: [s.n.] ,2012.

SANTOS, Magda / A Abordagem das Políticas Públicas Educacionais para Além Da Relação Estado E Sociedade / In:Seminário de Pesquisa em Educação da Região Sul / 2012 / Disponível em: <http://www.ucs.br/etc/conferencias/index.php/anpedsul/9anpedsul/paper/viewFile/2046/147> /Acesso em: 19 jan. 2016

SOUZA, Rosa Fatima / Lições da Escola Primária: Um Estudo sobre a cultura escolar paulista ao longo do século XX / Projeto de pesquisa da Unesp campus de Araraquara/ Disponível em: http://www.sbhe.org.br / Acesso em: 19 jan. 2016

TEIXEIRA, E. As três metodologias. 2a ed. São Paulo: Vozes, 2000. 